\title{
FORT COLLINS SCIENCE CENTER
}

Ecosystem Dynamics Branch

\section{Interdisciplinary Research for Addressing Complex Natural Resource Issues across Landscapes and Time}

\section{Capabilities}

The Ecosystem Dynamics Branch of the Fort Collins Science Center offers an interdisciplinary team of talented and creative scientists with expertise in biology, botany, ecology, geology, biogeochemistry, physical sciences, geographic information systems (GIS), and remote-sensing, for tackling complex questions about natural resources. As demand for natural resources increases, the issues facing natural resource managers, planners, policy makers, industry, and private landowners are increasing in spatial and temporal scope, often involving entire regions, multiple jurisdictions, and long timeframes. Needs for addressing these issues include (1) a better understanding of biotic and abiotic ecosystem components and their complex interactions; (2) the ability to easily monitor, assess, and visualize the spatially complex movements of animals, plants, water, and elements across highly variable landscapes; and (3) the techniques for accurately predicting both immediate and long-term responses of system components to natural and human-caused change. The overall objectives of our research are to provide the knowledge, tools, and techniques needed by the U.S. Department of the Interior, state agencies, and other stakeholders in their endeavors to meet the demand for natural resources while conserving biodiversity and ecosystem services.

Ecosystem Dynamics scientists use field and laboratory research, data

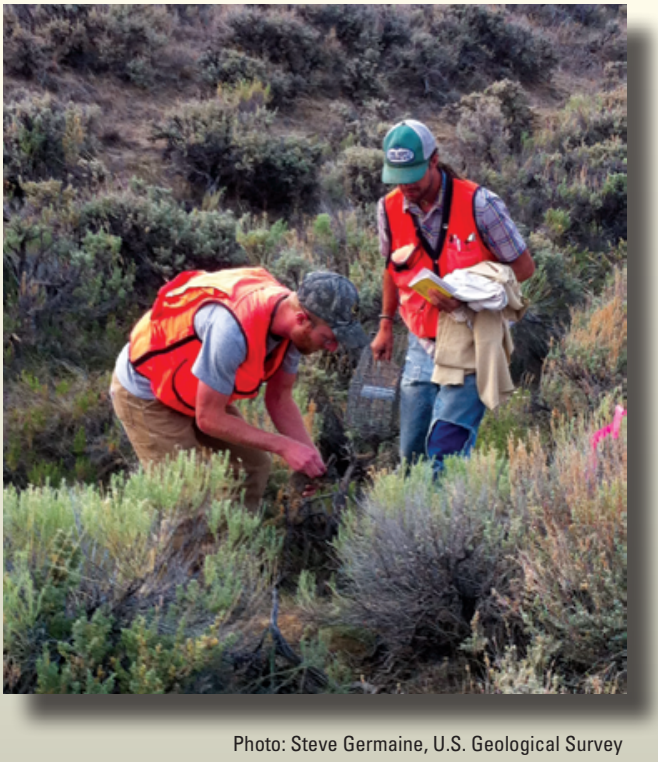
assimilation, and ecological modeling to understand ecosystem patterns, trends, and mechanistic processes. This information is used to predict the outcomes of changes imposed on species, habitats, landscapes, and climate across spatiotemporal scales. The products we develop include conceptual models to illustrate system structure and processes; regional baseline and integrated assessments; predictive spatial and mathematical models; literature syntheses; and frameworks or protocols for improved ecosystem monitoring, adaptive management, and program evaluation. The descriptions below provide snapshots of our three research emphases, followed by descriptions of select current projects.

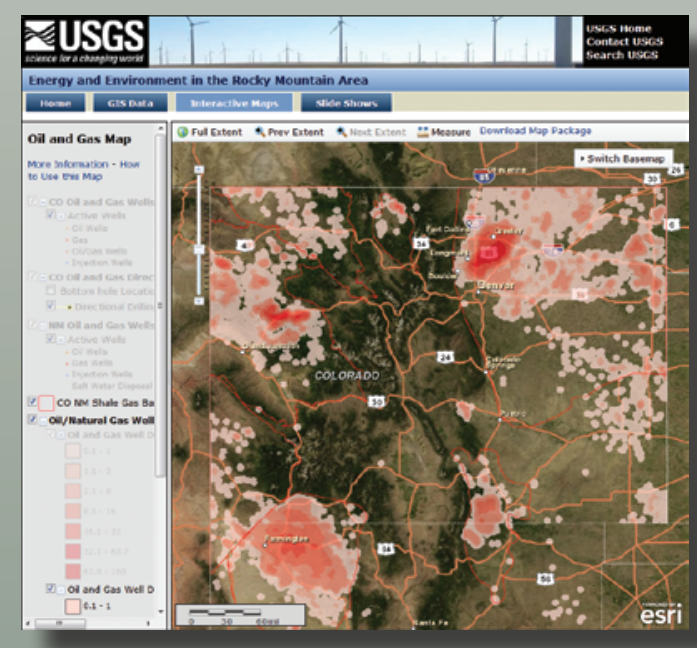

\section{Energy Development and Changing Land Uses}

Applied research and integrated regional assessments emphasize spatially explicit analyses of ecosystem components affected by energy development and land-use change in the western United States. Topics include sagebrush-steppe ecology; sagebrush habitat assessments; the effects of human activities (including energy development, transportation, and recreation) on habitats and wildlife behavior; habitat fragmentation and migration corridors; and technical assistance development for managers and decision makers.

Screen capture from an interactive map viewer showing oil and gas well density.

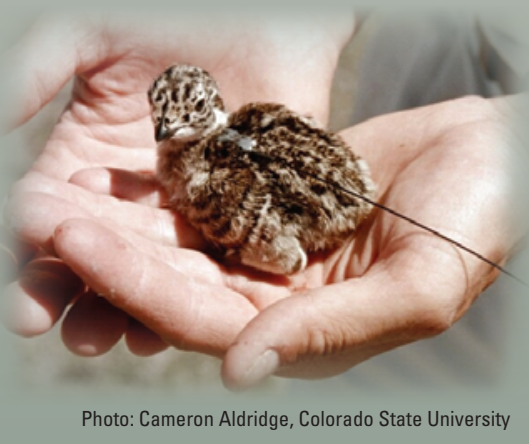


Research on Federal trust lands, especially in the mountains of western national parks and forests, addresses long-term ecosystem dynamics associated with climate change and atmospheric deposition of pollutants such as nitrogen. Studies include ecosystem biogeochemistry, nitrogen deposition, forest dieback, and assessment of forest biomes ranging from the Arctic to the desert Southwest. Our scientists are collaborating with researchers from around the world to describe and document global patterns of climate-induced forest dieback and the effects of atmospheric deposition on mountain ecosystems.

\section{Herbivore-Ecosystem Interactions}

Data from these studies help inform management decisions regarding ungulates on public lands, typically in large, jurisdictionally complex landscapes. Recent work involves investigations on the effects of herd size and movements of elk, bison, and wild horses on various ecosystem components. Specifically, scientific efforts include (1) quantifying interactions among herbivores, plants, and soils; (2) determining the effects of ungulate herbivory on ecosystem processes and vegetation communities; (3) testing survey techniques for more accurate population estimates; and (4) evaluating contraceptive methods for managing wild horse populations.

\section{Selected Projects}

\section{Energy and Land Use- Research and Technical Assistance}

Exploration and development of domestic energy resources have become national priorities, yet the direct and indirect effects of energy development on surrounding ecosystems remain poorly understood. This poses a challenge for natural resource managers who must balance priorities that include maintaining healthy rangelands and wildlife habitats while providing for resource development and multiple public uses. In collaboration with other Fort Collins Science Center branches, several other USGS science centers, and partners from Federal, state, and local agencies, we are conducting interdisciplinary research to provide the information, techniques, and tools that resource managers and other stakeholders need to address these issues at regional levels in the western United States. This work contributes directly to the Wyoming Landscape Conservation Initiative, a long-

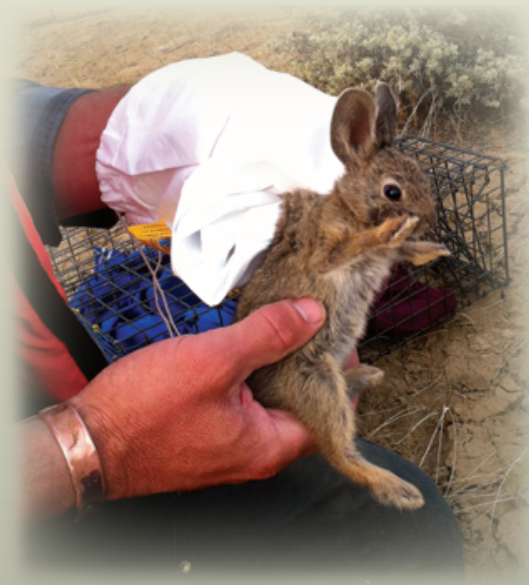

Photo: Steve Germaine, U.S. Geological Survey term, landscape-scale science collaboration to ensure full consideration of and adaptive management for Wyoming's wildlife and habitats as land-use pressures increase. Our energy and land-use work also involves (1) assessing and developing innovative tools for monitoring sagebrush habitat conditions; (2) developing targeted research and monitoring plans or frameworks; (3) identifying and assessing the ecological impacts of energy development, grazing, fire, roads and traffic, and climate change on sagebrush, aspen, and mountain shrubland ecosystems and species; (4) refining scientific understanding of sage-grouse population dynamics and genetics, pygmy rabbit demography and habitat use, and raptor habitat use; and (5) developing predictive models and maps that address management priorities.

\section{Western Mountain Ecosystem Responses to Climate Change}

The Ecosystem Dynamics Branch is participating in the Western Mountain Initiative, a cooperative effort to understand and predict the sensitivities, thresholds, resistance, and resilience of western mountain ecosystems to climatic variability and change. Our scientists are helping to develop comparative analyses of hydrological, ecological, and disturbance responses of watersheds in select mountain regions in Colorado, New Mexico, Montana, Oregon, Washington, and California to better understand current climate variability and predict future climate changes. Additionally, we are (1) continuing long-term ecological research and monitoring of the Loch Vale Watershed in Rocky Mountain National Park, Colo.; (2) studying the processes involved and the geographic extent of biogeochemical changes to headwaters ecosystems of the western United States in response to glacial melting and rock weathering; (3) conducting workshops for public land managers to help them develop and implement resource management measures that promote ecosystem resilience to climate change and reduce the risk of undesirable environmental outcomes; (4) continuing longterm ecological research and monitoring of ecohydrological responses in a semiarid watershed, as well as vegetation and tree growth along elevational gradients, in Bandelier 
National Monument, N. Mex.;

(5) clarifying centennial- to millennial-length shifts in past vegetation and fire regimes;

(6) elucidating responses of fire to short-term climatic variation; (7) determining long- and shortterm climatic controls of tree mortality, including thresholds for die-off; (8) documenting rapid and extensive climateinduced vegetation mortality, including global patterns of

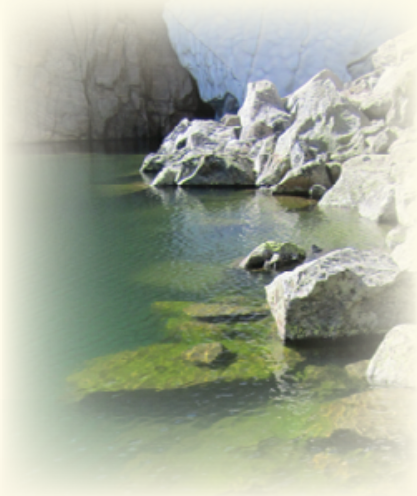

Photo: Jared Heath, Colorado State University massive forest dieback; (9) determining the effects of climatic variability, fire, and land use on watershed runoff and erosion processes; and (10) supporting hydroecological model development as a tool for evaluating our understanding of the processes listed above and projecting future conditions under various climate-change scenarios. Our scientists also served as lead authors on several recent reports to the U.S. Congress by the U.S. Climate Change Research Program and the Subcommittee on Global Change Research.

\section{Ecological Effects of Nitrogen and Sulfur Deposition}

Disruption of the global nitrogen cycle is a major global change affecting ecosystems and the services they provide for society. We seek to understand the processes and fate of reactive nitrogen that is deposited on protected ecosystems, such as those in national parks and preserves. Five major approaches are routinely used to address questions about how excess reactive nitrogen influences biodiversity, nutrient cycling, water quality, and aquatic ecosystems: (1) long-term monitoring (especially in Loch Vale Watershed, Rocky Mountain National Park, Colo.), (2) field and laboratory experiments, (3) spatial comparisons, (4) paleoecological reconstructions of past conditions, and (5) ecosystem modeling. Results of the research and synthesis have been used to inform international policy dialogue for the Convention on Biological Diversity and the Convention on Long-Range Transboundary Air Pollution. At a national level, this work is helping to set critical loads, or thresholds, below which there are no discernable effects from atmospheric nitrogen deposition for lakes in the United States. We also provide state-of-the-art modeling on how climate change and nitrogen deposition interact to influence mountain ecosystems.

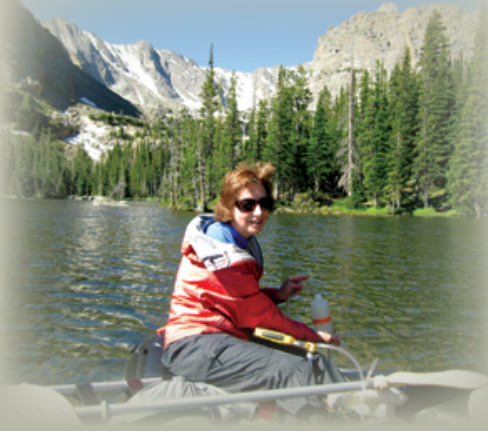

Photo: Jared Heath, Colorado State University
The cumulative body of knowledge generated from the Loch Vale Watershed has been used to set emissions reduction policy for the State of Colorado, and the success of that policy will be determined from measurements collected over the next 20 years from Rocky Mountain National Park.

\section{Elk and Bison Grazing Ecology in Great Sand Dunes National Park and Preserve}

Ecosystem Dynamics scientists are conducting studies on bison and elk in the Great Sand Dunes National Park and Preserve to determine population status and movements, the effects of herbivory, and suitable habitat and population potential in the park and surrounding lands. Scientists are using these data to develop an elk and bison grazing model that treats grazing as a significant natural ecological process and incorporates protection of sensitive native-plant communities. Our scientists are using the study results to develop a predictive managementplanning model based on several potential management scenarios. These tools will provide direct support to park managers in developing and evaluating management alternatives for elk and bison.

\section{Research for Management of America's Wild Horses}

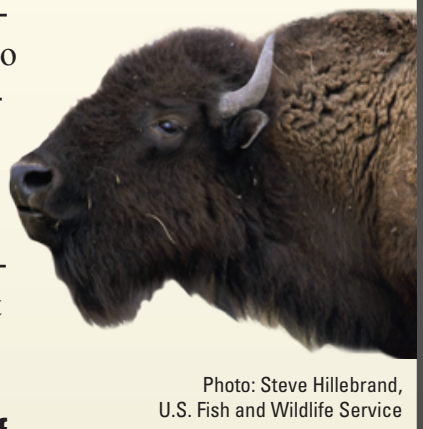

Since the U.S. Congress passed The Wild FreeRoaming Horses and Burros Act of 1971, natural resource managers have sought effective tools for managing these animals on Federal lands. Wild horse populations can grow at rates of 18-25 percent per year, because they are largely unchecked by natural predators. This unregulated growth can overtax vegetation and affect native wildlife populations. Ecosystem Dynamics scientists, in collaboration with the Bureau of Land Management, National Park Service, U.S. Department of Agriculture's Animal and Plant Health Inspection Service, and Colorado State University, are conducting research on fertility control for limiting population growth in wild horses. This research focuses on the immunocontraceptive vaccine, porcine zona pellucida (PZP), and investigates its effect on fertility, as well as potential side-effects, such as injection-site reactions, behavior modifications, and the temporal distribution of births. Additional research is being conducted on GonaCon, the gonadotropin-releasing hormone vaccine, and an alternative form of PZP called SpayVac*. We are also evaluating aerial survey techniques for estimating population size of wild horses and related species. This research focuses on synergistically combining several known abundance estimation techniques, such as simultaneous double-count, mark-resight, distance sampling, and sightability bias correction modeling, to alleviate shortfalls of the individual techniques and generate better estimates of population size with scientifically defensible confidence intervals.

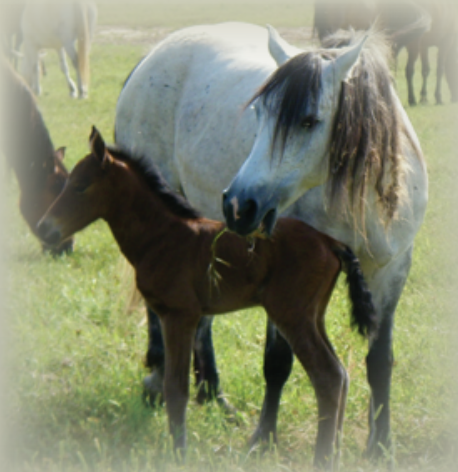

Photo: Carrie English, U.S. Geological Survey 


\section{Raptors and Wind Development-Developing Science- Based Tools for Conservation Planning}

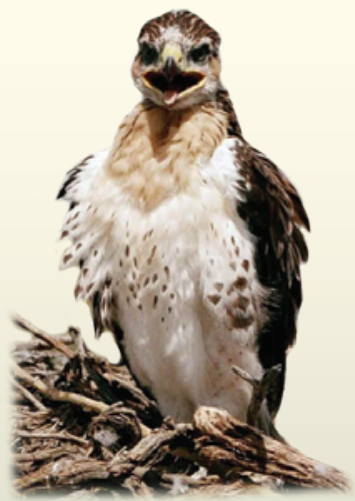

Photo: Cameron Aldridge, Colorado State University ment corridors. To address these limitations, priority raptor habitats in Wyoming need to be identified. The primary goal of this project is to develop a quantitative, predictive model that describes the relationship between available habitat and habitat use for four raptor species in Wyoming: Golden Eagle, Ferruginous Hawk, Northern Harrier, and Prairie Falcon. Our project will result in models and maps that identify priority raptor habitat areas. In turn, these products will promote effective raptor conservation by facilitating the prioritization of locations for strategic, focused conservation efforts. If proven effective, the models and techniques may be expanded to identify priority raptor habitats in other regions.

\section{Contact Information}

\author{
Zachary Bowen, Branch Chief, Ecosystem Dynamics \\ U.S. Geological Survey \\ Fort Collins Science Center \\ 2150 Centre Avenue, Building C \\ Fort Collins, Colorado 80526-8118 \\ Tel. 970.226 .9218 Fax 970.226 .9230 \\ bowenz@usgs.gov
}

Learn more about FORT science, products, and resources at http://www.fort.usgs.gov

Learn more about the Ecosystem Dynamics Branch at: http://www.fort.usgs.gov/ED/

\section{Staff}

Ecosystem Dynamics research staff possess extensive education and experience in ecology, wildlife biology, botany, population ecology and dynamics, habitat and population modeling, climate change, natural and humancaused perturbations, biogeochemistry, geology, fire science, and spatial analysis.

\section{Branch Chief: Zachary Bowen, Ph.D., Supervisory Ecologist, bowenz@usgs.gov}

Aldridge, Cameron, Ph.D., Scientist (Colorado State University contractor), aldridgec@usgs.gov

Allen, Craig, Ph.D., Research Ecologist, craig_allen@usgs.gov

Anderson, Patrick, M.S., General Biologist, andersonpj@usgs.gov

Assal, Timothy, Ph.D.Candidate, Ecologist, assalt@usgs.gov

Baron, Jill, Ph.D., Research Ecologist, jill_baron@usgs.gov or jill@nrel.colostate.edu Carr, Natasha, Ph.D., Ecologist, carrn@usgs.gov

Germaine, Stephen, M.S., Ecologist,germaines@usgs.gov

Hall, Edward, Ph.D., Research Biologist, ehall@usgs.gov

Manier, Daniel, Ph.D., Research Manager III (Cherokee Services Group contractor), manierd@usgs.gov

Mask, Tracy, M.S. Candidate, Biological Science Technician,tmask@usgs.gov

McDougal, Robert, M.S., Geologist, rmcdougal@usgs.gov

Melcher, Cynthia, M.S., Wildlife Biologist, melcherc@usgs.gov

Ouren, Douglas, M.S., Physical Scientist, ourend@usgs.gov

Roelle, James, Ph.D., Supervisory Fish and Wildlife Biologist, roelleb@usgs.gov

Saher, Joanne, M.S., Scientist (Colorado State University contractor), saherj@usgs.gov

Schell, Spencer, B.S., Ecologist, schells@usgs.gov

Schoenecker, Kathryn, Ph.D. Candidate, Ecologist, schoeneckerk@usgs.gov

Tack, Jason, Ph.D. Candidate, Biologist, jtack@usgs.gov

Wann, Gregory, Ph.D. Candidate, Science Technician,wanng@usgs.gov

Zeigenfuss, Linda, M.S., Wildlife Biologist, linda_zeigenfuss@usgs.gov

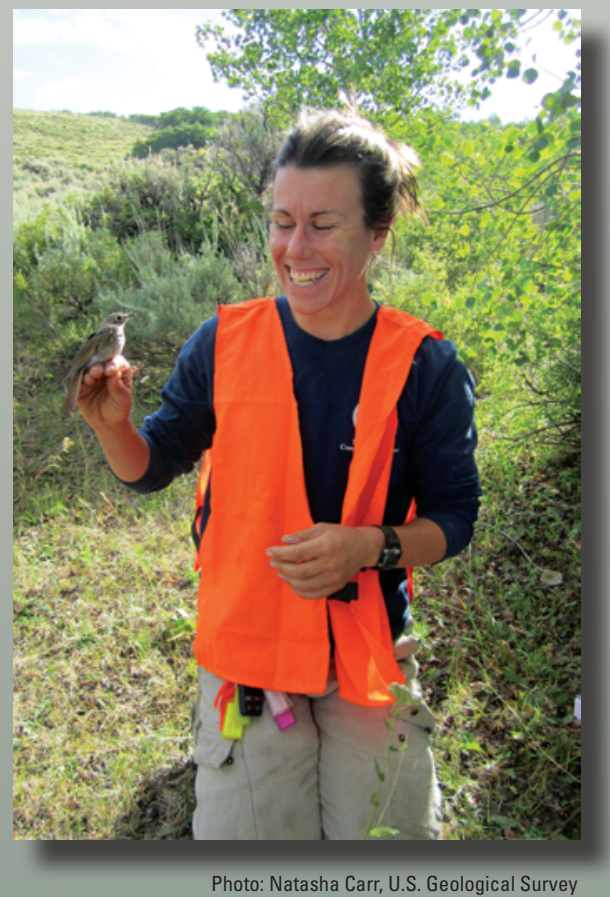

